\title{
Magneto Convective Flow of a Non-Newtonian Fluid through Non-Homogeneous Porous Medium past a Vertical Porous Plate with Variable Suction
}

\author{
S. Harinath Reddy ${ }^{1}$, M. C. Raju ${ }^{1}$, E. Keshava Reddy ${ }^{2}$ \\ ${ }^{1}$ Department of Humanities and Sciences, Annamacharya Institute of Technology and Sciences (Autonomous), \\ Rajampet, India \\ ${ }^{2}$ Department of Mathematics, Jawaharlal Nehru Technological University, Hyderabad, India \\ Email:mcrmaths@yahoo.co.in
}

Received 29 December 2015; accepted 19 February 2016; published 22 February 2016

Copyright $(02016$ by authors and Scientific Research Publishing Inc.

This work is licensed under the Creative Commons Attribution International License (CC BY). http://creativecommons.org/licenses/by/4.0/

(c) (1) Open Access

\begin{abstract}
Radiation absorption and chemical reaction effects on unsteady MHD free convective flow of a visco-elastic fluid past a vertical porous plate in the presence of variable suction and heat source is considered. A uniform magnetic field is assumed to be applied in the transverse direction of the flow. The set of non-linear partial differential equations is transformed into a set of ordinary differential equations by super imposing a solution with steady and unsteady part. The set of ordinary differential equations is solved by using regular perturbation scheme. The expressions for velocity, temperature and species concentration fields are obtained and the expressions for Skin friction, Nusselt number and Sherwood number are also derived. The effects of numerous physical parameters on the above flow quantities are studied with the help of graphs and tables.
\end{abstract}

\section{Keywords}

MHD, Visco-Elastic Fluid, Unsteady Flow, Chemical Reaction, Radiation Absorption, Suction

\section{Introduction}

MHD free convection fluid flows frequently occur in natural world. Fluid passes through porous medium are of great interest nowadays and many researchers attract towards the applications in the fields of science and technology namely in the area of agriculture engineering to know about the ground water resources, in fuel technol- 
ogy to study the moment of natural gas, oil, and water through the oil reservoirs. Chaudhary et al. [1] considered Hall effect on MHD mixed convection flow of a visco-elastic fluid past an infinite vertical porous plate with mass transfer and radiation. Satyanarayana et al. [2] discussed MHD free convective heat and mass transfer past a vertical porous plate with variable temperature. Kesavaiah et al. [3] studied and presented effects of chemical reaction and radiation absorption on unsteady MHD convection heat and mass transfer flow past a semi-infinite vertical permeable moving plate embedded in porous medium with heat source and suction. Reddy et al. [4] considered effects of chemical reaction and radiation absorption on unsteady magnetohydrodynamic double diffusive convective flow of viscous fluid past a semi-infinite porous plate. Raju et al. [5] investigated radiation and mass transfer effects on a free convection flow through porous medium bounded by a vertical surface. Muthukumaraswamy et al. [6] analyzed first order chemical reaction on flow past an impulsively started vertical plate with uniform heat and mass flux. Das et al. [7] studied the effects of mass transfer on a flow past an impulsively started infinite vertical plate with constant heat flux and chemical reaction. Kandaswamy et al. [8] focused on the problem of chemical reaction, heat and mass transfer on magnetohydrodynamic flow over a vertical stretching surface with heat source and thermal stratification effects. Effects of chemical reaction and thermophoresis on MHD mixed convective heat and mass transfer flow along an inclined plate in the presence of heat generation/absorption with viscous dissipation and joule heating was considered by Alam et al. [9]. Muthucumaraswamy et al. [10] analyzed the effects of chemical reaction on moving infinite vertical plate with uniform heat flux and variable mass diffusion. Mahapatra et al. [11] investigated the effect of chemical reaction on free convection flow through a porous medium bounded by a vertical surface. Mishra et al. [12] considered the effect of mass and heat transfer on magnetohydrodynamic flow of a visco-elastic fluid through porous medium with oscillatory suction and heat source. Beget et al. [13] had established computational fluid dynamics modeling of bouncy induced visco-elastic flow in a porous medium with magnetic field effect. Soundalgekar et al. [14] investigated effects of mass transfer and natural convection effects on MHD stokes problem for a vertical plate. Kandasamy et al. [15] studied the effects of chemical reaction, heat and mass transfer along a wedge with heat source and concentration in the presence of source or injection. Gurmindersingh et al. [16] analyzed the mass transfer with chemical reaction in MHD mixed convection flow along a vertical stretching sheet. Radiation effects on MHD free convection flow over a vertical plate with heat and mass flux was considered by Sivaiah et al. [17]. Sahim et al. [18] considered Laplace technique on MHD radiating and chemically reacting fluid over an infinite vertical surface. Singh et al. [19] investigated heat and mass transfer in MHD flow of a viscous fluid past a vertical plate under oscillatory suction velocity. Reddy et al. [20] had presented thermal radiation and chemical reaction effects on magnetohydrodynamic mixed convective boundary layer slip flow in a porous medium with heat source and Ohmic heating. Rout et al. [21] studied effect of radiation and chemical reaction on free convective MHD flow through a porous medium with double diffusion. Effects of chemical reaction and radiation absorption on MHD flow of dusty visco-elastic fluid were considered by Prakash et al. [22]. Damala et al. [23] discussed radiation absorption, chemical reaction and magnetic field effects on the free convection and mass transfer flow through porous medium with constant suction and constant heat flux. Raju et al. [24] studied unsteady MHD free convection and chemically reactive flow past an infinite vertical porous plate. Umamaheswar et al. [25] investigated unsteady MHD free convective visco-elastic fluid flow bounded by an infinite inclined porous plate in the presence of heat source, viscous dissipation and Ohmic heating. Reedy et al. [26] considered chemical reaction and radiation effects on unsteady MHD free convection flow near a moving vertical plate. Rajesh et al. [27] studied radiation effects on MHD flow through a porous medium with variable temperature or variable mass diffusion. Kesavaiah et al. [28] investigated radiation and mass transfer effects on moving vertical plate with variable temperature and viscous dissipation. Recently Ravikumar et al. [29] investigated combined effects of heat absorption and MHD on convective Rivlin-Ericksenflow past a semi-infinite vertical porous plate. And Venkateswarlu et al. [30] had presented chemical reaction and radiation absorption effects on the flow and heat transfer of a Nano fluid in a rotating system.

The objective of the present paper is to analyze radiation absorption and chemical reaction on MHD visco-elastic free convection flow through porous medium bounded by a vertical surface with constant heat and mass flux in the presence of homogeneous chemical reaction. The dimensionless equations of continuity, linear momentum, energy and diffusion which governed the flow field were solved using perturbation technique. The behavior of velocity, temperature, concentration and skin friction coefficient was discussed for various parameters involved in the governing equations the applicable criteria that follow. 


\section{Formulation of the Problem}

The unsteady free convection, viscous incompressible electrically conducting flow of a radiation absorption, chemically reacting and visco-elastic (Walters $\mathrm{B}^{*}$ ) fluid past asemi-infinite vertical porous plate in a porous medium with variable suction as well as permeability in presence of a transverse magnetic field is considered. Let $\mathrm{x}^{*}$-axis be along the plate in the direction of the fluid flow and $\mathrm{y}^{*}$-axis perpendicular to it. It is assumed that, magnetic Reynolds number is much less than unity so that the induced magnetic field is neglected in comparison with the applied transverse magnetic field. The basic flow in the medium is therefore, entirely due to the buoyancy force caused by the temperature difference between the wall and the medium. This assumed that initially, at $t^{*} \leq 0$,the plate as well as fluids are at the same temperature and concentration. As the concentration of the species is very low so that the Soret and Dofour effects are neglected. When $t^{*}>0$, the temperature of the plate is instantaneously raised to $T_{w}^{*}$ and the concentration of the species is set to $C_{w}^{*}$ (see Figure 1).

It is considered that the permeability of the porous medium in the following form

$$
K^{*}\left(t^{*}\right)=K_{p}^{*}\left(1+\varepsilon \mathrm{e}^{n^{*} t^{*}}\right)
$$

where $K^{*}\left(t^{*}\right)$ is $K_{p}^{*}$ is porosity, $\omega^{*}$ is frequency of oscillation, $t^{*}$ is time, $\varepsilon$ is a small positive constant.

The suction velocity is assumed to be time varying and it takes the following form

$$
v\left(t^{*}\right)=-v_{0}\left(1+\varepsilon \mathrm{e}^{n^{*} t^{*}}\right)
$$

Here $v_{0}>0$ and $\varepsilon \ll 1$ are positive constants. Under the above assumptions with usual Boussineq's approximation (Mishra et al. [31], Raju and Varma [32] [33]), the governing equations and boundary conditions are given by

$$
\begin{aligned}
& \frac{\partial u^{*}}{\partial t^{*}}+v \frac{\partial u^{*}}{\partial y^{*}}=v \frac{\partial^{2} u^{*}}{\partial y^{* 2}}+g \beta\left(T^{*}-T_{\infty}\right)+g \beta^{*}\left(C^{*}-C_{\infty}\right)-\frac{\sigma B_{0}^{2}}{\rho} u^{*} \\
& -\frac{v u^{*}}{\kappa_{p}^{*}\left(1+\varepsilon \mathrm{e}^{i w^{*} t^{*}}\right)}-\frac{k_{0}}{\rho}\left(\frac{\partial^{3} u^{*}}{\partial t^{*} \partial y^{*^{2}}}+v \frac{\partial^{3} u^{*}}{\partial y^{*^{3}}}\right) \\
& \frac{\partial T^{*}}{\partial t^{*}}+v \frac{\partial T^{*}}{\partial y^{*}}=\kappa \frac{\partial^{2} T^{*}}{\partial y^{* 2}}+s^{*}\left(T^{*}-T_{\alpha}\right)-R^{*}\left(C^{*}-C_{\alpha}\right) \\
& \frac{\partial C^{*}}{\partial t^{*}}+v \frac{\partial C^{*}}{\partial y^{*}}=D \frac{\partial^{2} C^{*}}{\partial y^{* 2}}-k^{*}\left(C^{*}-C_{\alpha}\right) \\
& \overbrace{0} \longrightarrow \text { Thermal b } 1
\end{aligned}
$$

Figure 1. Physical configuration and coordinate geometry. 


$$
\begin{array}{ll}
u=0, T^{*}=T_{\infty}+\varepsilon\left(T_{\omega}-T_{\infty}\right) \mathrm{e}^{n^{n^{*}}}, C^{*}=C_{\infty}+\varepsilon\left(C_{\omega}-C_{\infty}\right) \mathrm{e}^{n^{* t^{*}}} \text { at } y=0, \\
u \rightarrow 0, T^{*} \rightarrow T_{\infty}, C^{*} \rightarrow C_{\infty} & \text { as } y \rightarrow \infty
\end{array}
$$

Introducing the non-dimensional quantities,

$$
\begin{aligned}
& y=\frac{v_{0} y^{*}}{v}, t=\frac{v_{0}^{2} t^{*}}{4 v}, \omega=\frac{4 v \omega^{*}}{v_{0}^{2}}, u=\frac{u^{*}}{v_{0}}, T=\frac{T^{*}-T_{\alpha}}{T_{w}-T_{\infty}}, C=\frac{C^{*}-C_{\infty}}{C_{w}-C_{\infty}}, \\
& S=\frac{v S^{*}}{v_{0}^{2}}, \kappa_{p}=\frac{v_{0}^{2} k_{p}^{*}}{v^{2}}, M^{2}=\frac{\sigma B_{0}^{2}}{\rho} \frac{v}{v_{0}^{2}}, P_{r}=\frac{v}{k}, G_{c}=\frac{v g \beta^{*}\left(C_{w}-C_{\infty}\right)}{v_{0}^{3}}, \\
& G_{r}=\frac{v g \beta\left(T_{w}-T_{\infty}\right)}{v_{0}^{3}}, S_{c}=\frac{v}{D}, R_{c}=\frac{k_{0} v_{0}^{2}}{\rho v^{2}}, \kappa_{r}=\frac{k^{*} v}{v_{0}^{2}}, R_{1}=\frac{v\left(C_{w}-C_{\infty}\right) R^{*}}{v_{0}^{2}\left(T_{w}-T_{\infty}\right)}
\end{aligned}
$$

The Equations (3) to (5) are reduced to the following dimensionless equations

$$
\begin{aligned}
& \frac{1}{4} \frac{\partial u}{\partial t}-\left(1+\varepsilon \mathrm{e}^{n t}\right) \frac{\partial u}{\partial y}=\frac{\partial^{2} u}{\partial y^{2}}+ G_{r} T+C G_{c}-M^{2} u-\frac{u}{K_{p}\left(1+\varepsilon \mathrm{e}^{n t}\right)}-R_{c}\left(\frac{1}{4} \frac{\partial^{3} u}{\partial t \partial y^{2}}-\left(1+\varepsilon \mathrm{e}^{n t}\right) \frac{\partial^{3} u}{\partial y^{3}}\right) \\
& \frac{1}{4} \frac{\partial T}{\partial t}-\left(1+\varepsilon \mathrm{e}^{n t}\right) \frac{\partial T}{\partial y}=\frac{1}{P_{r}} \frac{\partial^{2} T}{\partial y^{2}}+S T-R_{1} C \\
& \frac{1}{4} \frac{\partial C}{\partial t}-\left(1+\varepsilon \mathrm{e}^{n t}\right) \frac{\partial C}{\partial y}=\frac{1}{S_{c}} \frac{\partial^{2} C}{\partial y^{2}}-C \kappa_{r} \\
& u=0, T=1+\varepsilon \mathrm{e}^{n t}, C=1+\varepsilon \mathrm{e}^{n t} \quad \text { at } y=0 \\
& u \rightarrow 0, T \rightarrow 0, C \rightarrow 0 \quad \text { as } y \rightarrow \infty
\end{aligned}
$$

\section{Method of Solution}

In view of transient suction, temperature and concentration at the plate let us assume the velocity, temperature, concentration in the neighborhood of the plate.

$$
\begin{gathered}
u(y, t)=u_{0}(y)+\varepsilon u_{1}(y) \mathrm{e}^{n t}+o\left(\varepsilon^{2}\right) \\
T(y, t)=T_{0}(y)+\varepsilon T_{1}(y) \mathrm{e}^{n t}+o\left(\varepsilon^{2}\right) \\
C(y, t)=C_{0}(y)+\varepsilon C_{1}(y) \mathrm{e}^{n t}+o\left(\varepsilon^{2}\right)
\end{gathered}
$$

Substituting above Equations (12)-(14) into the Equations (8)-(10) and equating the $\varepsilon^{0}$ coefficient and coefficient of $\varepsilon^{1}$, we get the following equations.

$$
\begin{gathered}
R_{c} u_{0}^{111}+u_{0}^{11}+u_{0}^{1}-\left(M^{2}+\frac{1}{\kappa_{p}}\right) u_{0}=-C G_{c}-G_{r} T_{0} \\
R_{c} u_{1}^{111}+\left(1-\frac{n R_{c}}{4}\right) u_{1}^{11}+u_{1}^{1}-\left(M^{2}+\frac{1}{\kappa_{p}}+\frac{n}{4}\right) u_{1}=-u_{0}^{1}-G_{r} T_{1}-C_{1} G_{c}-\frac{u_{0}}{\kappa_{p}}-R_{c} u_{0}^{111} \\
T_{0}^{11}+P_{r} T_{0}^{1}+S P_{r} T_{0}=R_{1} P_{r} C_{0} \\
T_{1}^{11}+P_{r} T_{1}^{1}+P_{r}\left(S-\frac{n}{4}\right) T_{1}=P_{r}\left(R_{1} C_{1}-T_{0}^{1}\right) \\
C_{0}^{11}+S_{c} C_{0}^{1}-S_{c} \kappa_{r} C_{0}=0 \\
C_{1}^{11}+S_{c} C_{1}^{1}-S_{c}\left(\kappa_{r}+\frac{n}{4}\right) C_{1}=-S_{c} C_{0}^{1}
\end{gathered}
$$


Now the boundary conditions are reduced to the following forms

$$
\begin{array}{lll}
u_{0}=0, u_{1}=0, T_{0}=1, T_{1}=1, C_{0}=1, C_{1}=1 & \text { as } & y=0 \\
u_{0} \rightarrow 0, u \rightarrow 0, T_{0}=T_{1} \rightarrow 0, C_{0}=C_{1} \rightarrow 0 & \text { as } & y \rightarrow \infty
\end{array}
$$

The Equations (15) and (16) are not solvable by using the given boundary conditions (21). Hence the perturbation method has been applied using $R_{c}\left(R_{c}<1\right)$, the elastic parameter as the perturbation parameter.

$$
\begin{aligned}
& u_{0}=u_{00}(y)+R_{c} u_{01}(y)+o\left(R_{c}^{2}\right) \\
& u_{1}=u_{10}(y)+R_{c} u_{11}(y)+o\left(R_{c}^{2}\right)
\end{aligned}
$$

Substituting Equation (22) into Equations (15) and (16), equating the coefficients of $R_{c}{ }^{0}$ and $R_{C}{ }^{1}$ to zero, we get the following set of equations.

\section{Zeroth order equations}

$$
\begin{gathered}
u_{00}^{11}+u_{00}^{1}-\left(M^{2}+\frac{1}{\kappa_{p}}\right) u_{00}=-G_{c} C_{0}-G_{r} T_{0} \\
u_{01}^{11}+u_{01}^{1}-\left(M^{2}+\frac{1}{\kappa_{p}}\right) u_{01}=-u_{00}^{111}
\end{gathered}
$$

First order equations

$$
\begin{gathered}
u_{10}^{11}+u_{10}^{1}-\left(M^{2}+\frac{1}{\kappa_{p}}+\frac{n}{4}\right) u_{10}=-u_{00}^{1}-G_{r} T_{1}-G_{c} C_{1}-\frac{u_{00}}{\kappa_{p}} \\
u_{11}^{11}+u_{11}^{1}-\left(M^{2}+\frac{1}{\kappa_{p}}+\frac{n}{4}\right) u_{11}=-u_{01}^{1}-\frac{u_{01}}{\kappa_{p}}-u_{00}^{111}+\frac{n}{4} u_{10}^{11}-u_{10}^{111}
\end{gathered}
$$

Using the perturbation the boundary conditions are reduced as follows:

$$
\begin{array}{lll}
u_{00}=0, u_{01}=0, u_{10}=0, u_{11}=0 & \text { as } & y=0 \\
u_{00}=0, u_{01}=0, u_{10}=0, u_{11}=0 & \text { as } & y=\infty
\end{array}
$$

Solving these differential equations by using the boundary conditions we get the following results (Appendix)

$$
\begin{aligned}
& u=A_{44} \mathrm{e}^{-m_{11} y}+A_{45} \mathrm{e}^{-m_{9} y}+A_{46} \mathrm{e}^{-m_{5} y}+A_{47} \mathrm{e}^{-m_{1} y} \\
& +\varepsilon\left(A_{48} \mathrm{e}^{-m_{15} y}+A_{49} \mathrm{e}^{-m_{13} y}+A_{50} \mathrm{e}^{-m_{11} y}+A_{51} \mathrm{e}^{-m_{9} y}+A_{52} \mathrm{e}^{-m_{7} y}+A_{53} \mathrm{e}^{-m_{5} y}+A_{54} \mathrm{e}^{-m_{3} y}+A_{55} \mathrm{e}^{-m_{1} y}\right) \mathrm{e}^{n t} \\
& T=\left(1-A_{2}\right) \mathrm{e}^{-m_{5} y}+A_{2} \mathrm{e}^{-m_{1} y}+\varepsilon\left\{\left[1-\left(A_{6}+A_{7}+A_{8}\right)\right) \mathrm{e}^{-m_{7} y}+A_{6} \mathrm{e}^{-m_{3} y}+A_{7} \mathrm{e}^{-m_{1} y}+A_{8} \mathrm{e}^{-m_{5} y}\right\} \mathrm{e}^{n t} \\
& C=\mathrm{e}^{-m_{1} y}+\varepsilon\left\{\left(1-A_{1}\right) \mathrm{e}^{-m_{3} y}+A_{1} \mathrm{e}^{-m_{1} y}\right\} \mathrm{e}^{n t}
\end{aligned}
$$

The skin friction, Nusselt number and Sherwood number at the plate are defined as follows:

$$
\begin{aligned}
& \tau=-\frac{\partial u}{\partial y} \text { at } y=0 \\
& N u=\frac{\partial T}{\partial y} \text { at } y=0 \\
& S h=\frac{\partial C}{\partial y} \text { at } y=0
\end{aligned}
$$




\section{Results and Discussion}

The present study considers the effects of radiation absorption and chemical reaction effect on transient free convection flow of a non-Newtonian fluid through non-homogeneous porous medium past a vertical porous plate with magnetic field and variable suction. Solutions for velocity, temperature and concentration field are obtained by using perturbation technique. The effects of various parameters like Grashof number for heat and mass transfer $G r$ and $G c$, chemical reaction $K r$, Radiation absorption $R_{1}$, Prandtl number $P r$, on velocity, temperature and concentration have been studied analytically and effects are executed with the help of Figures 2-15. Also the behavior of skin friction, rate of heat transfer and rate of mass transfer with respect to various parameters have been studied and results were presented in Tables 1-10.

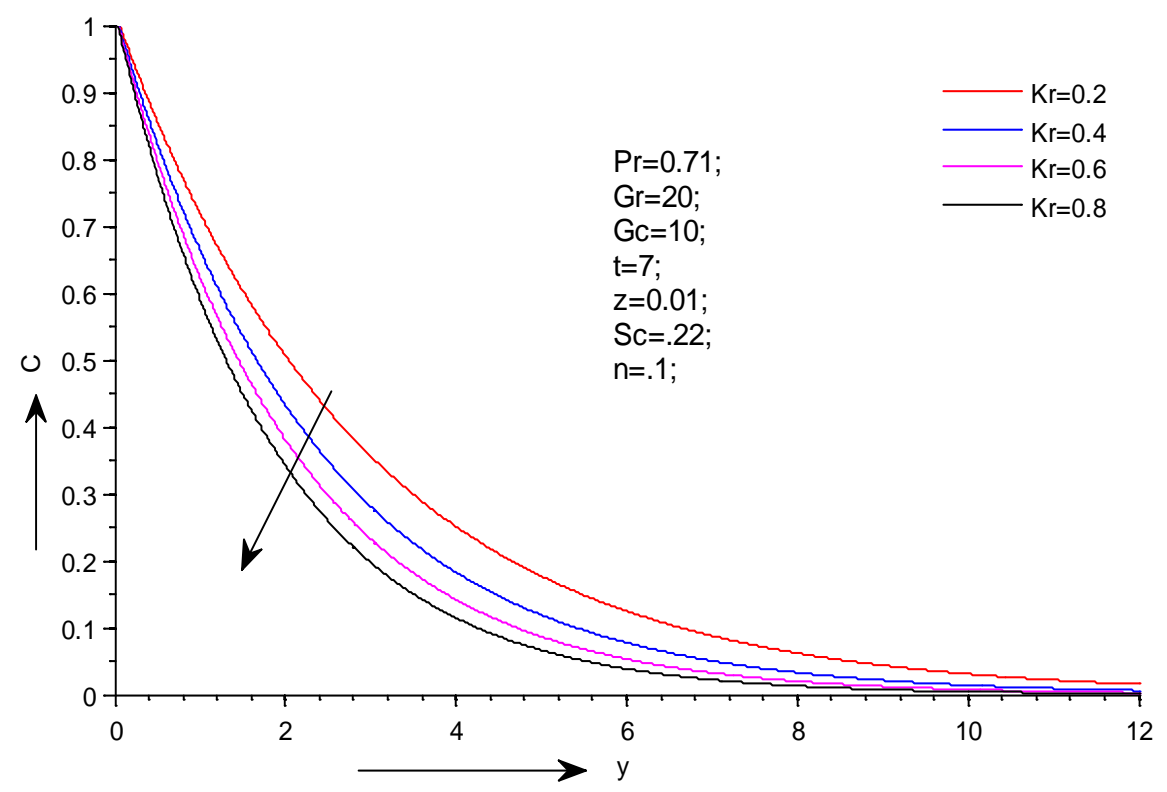

Figure 2. Effect of $\mathrm{Kr}$ on concentration.

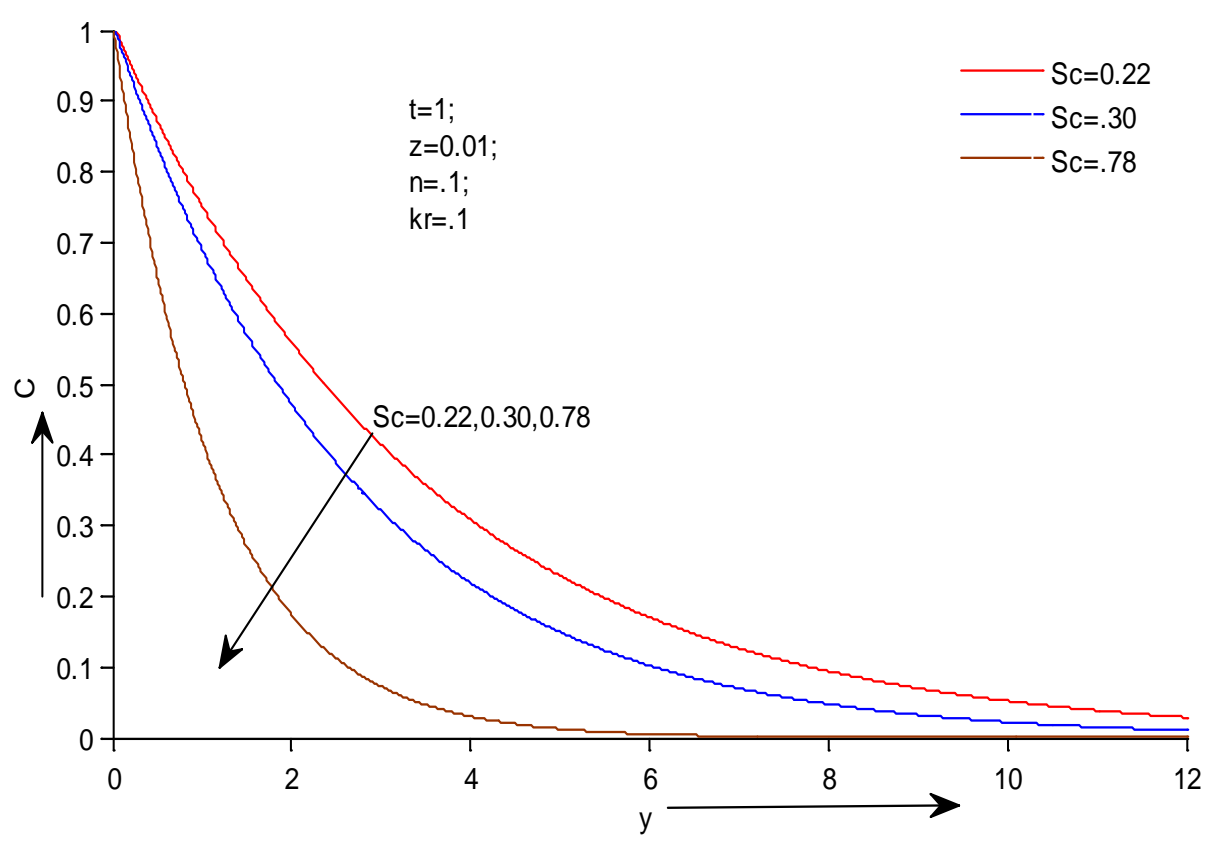

Figure 3. Effects of Sc on concentration. 


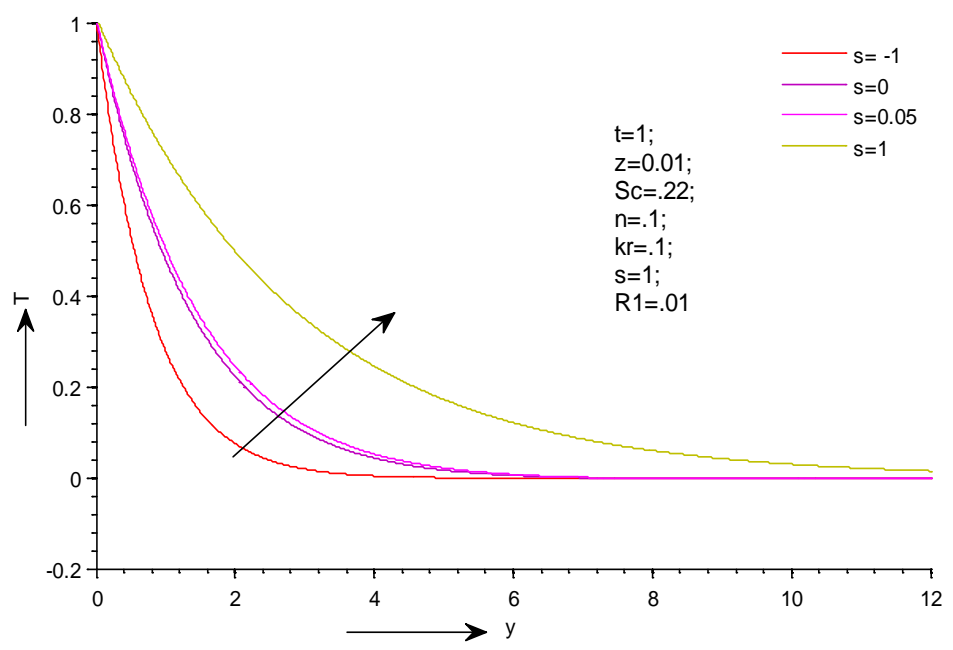

Figure 4. Effects of $S$ on temperature.

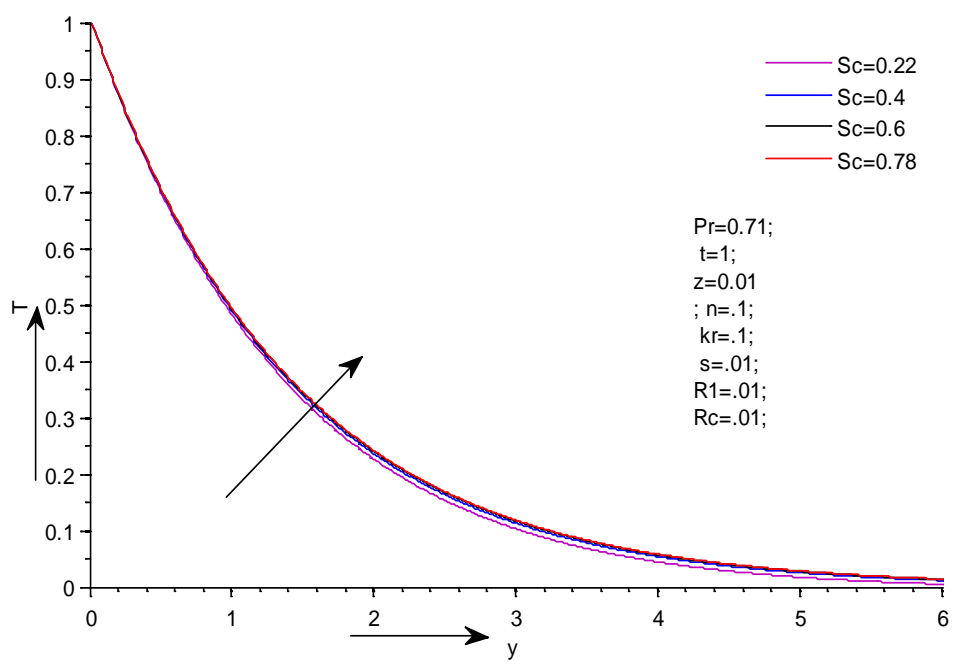

Figure 5. Effects of Sc on temperature.

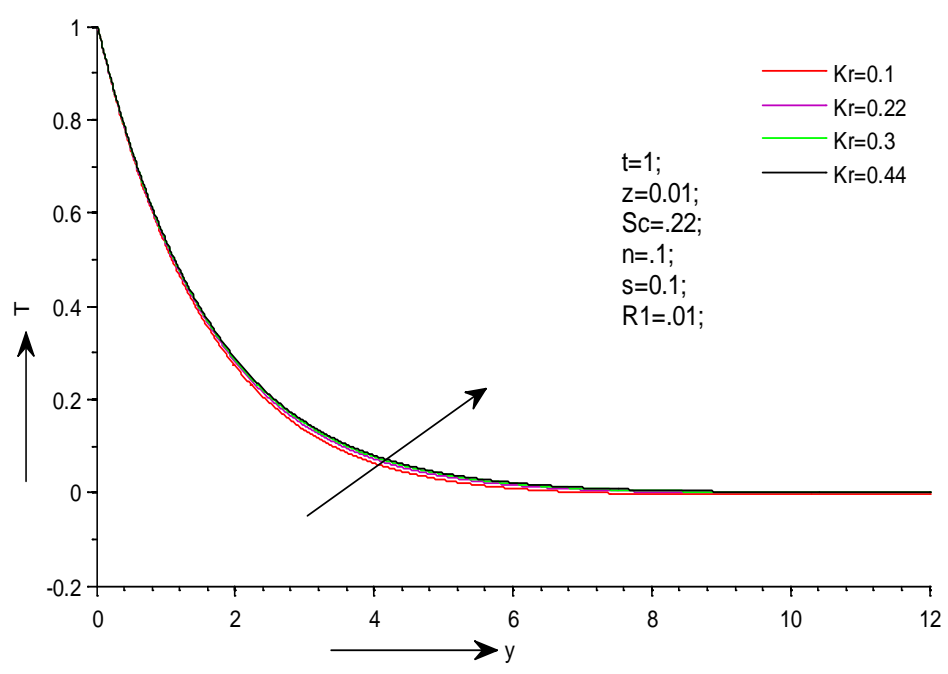

Figure 6. Effects of $\mathrm{Kr}$ on temperature. 


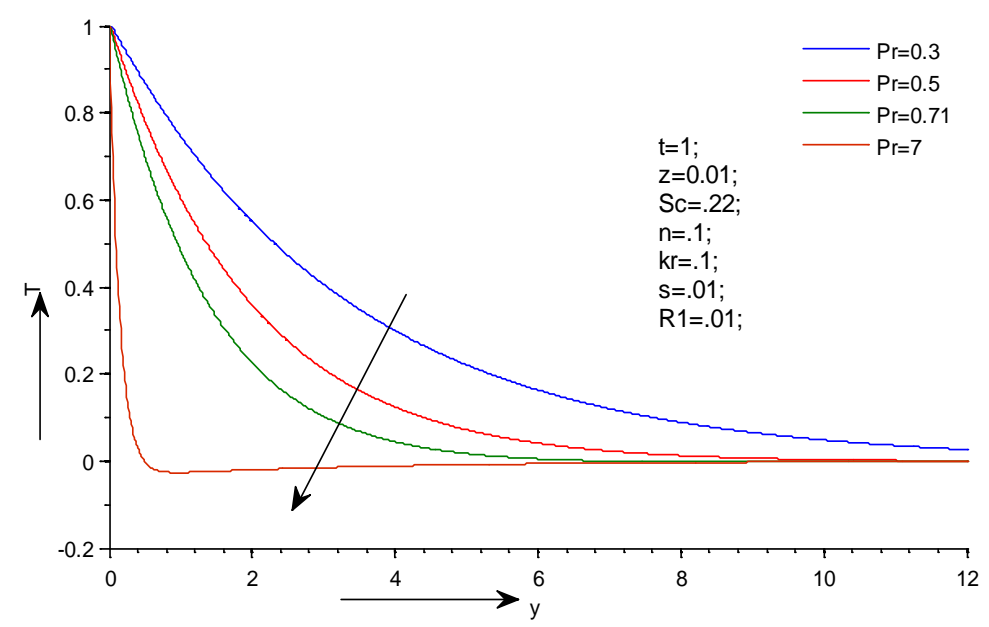

Figure 7. Effects of $\operatorname{Pr}$ on temperature.

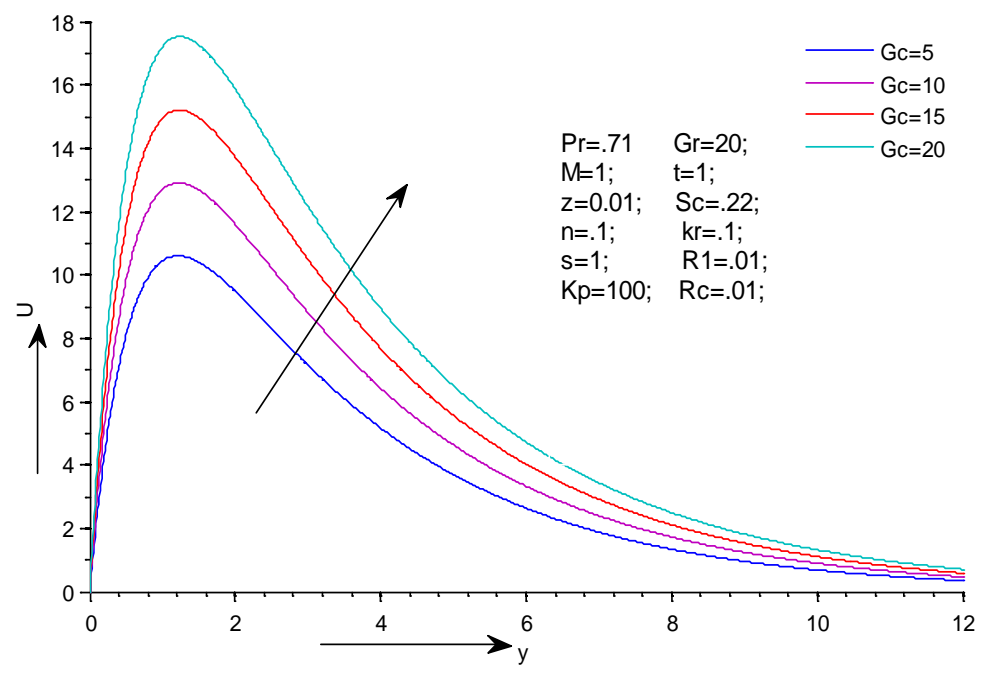

Figure 8. Effects of Gc on velocity.

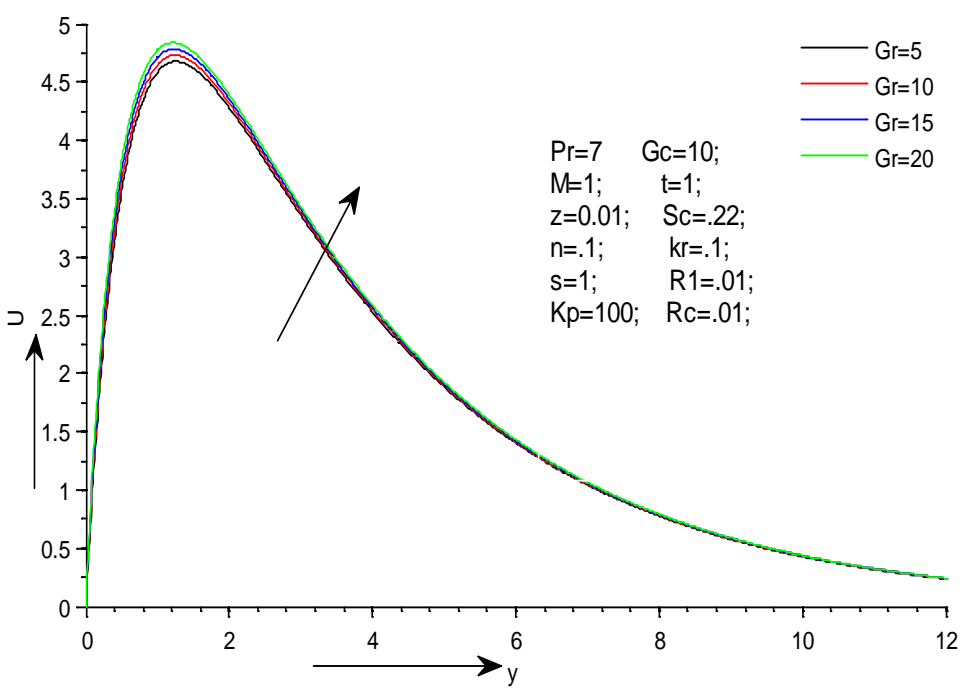

Figure 9. Effects of $\mathrm{Gr}$ on velocity. 


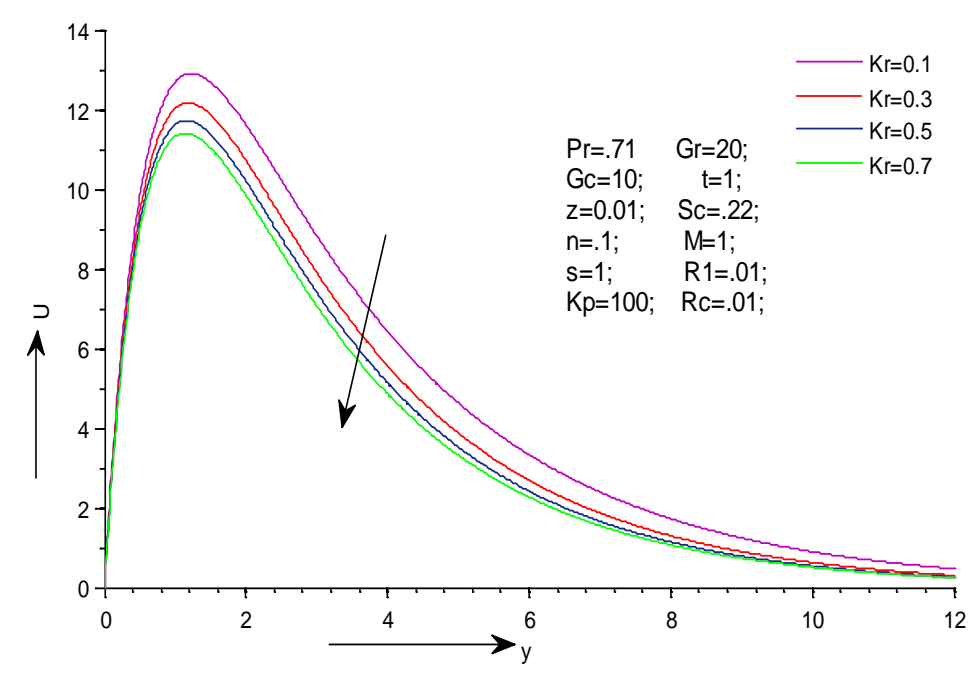

Figure 10. Effects of $K r$ on velocity.

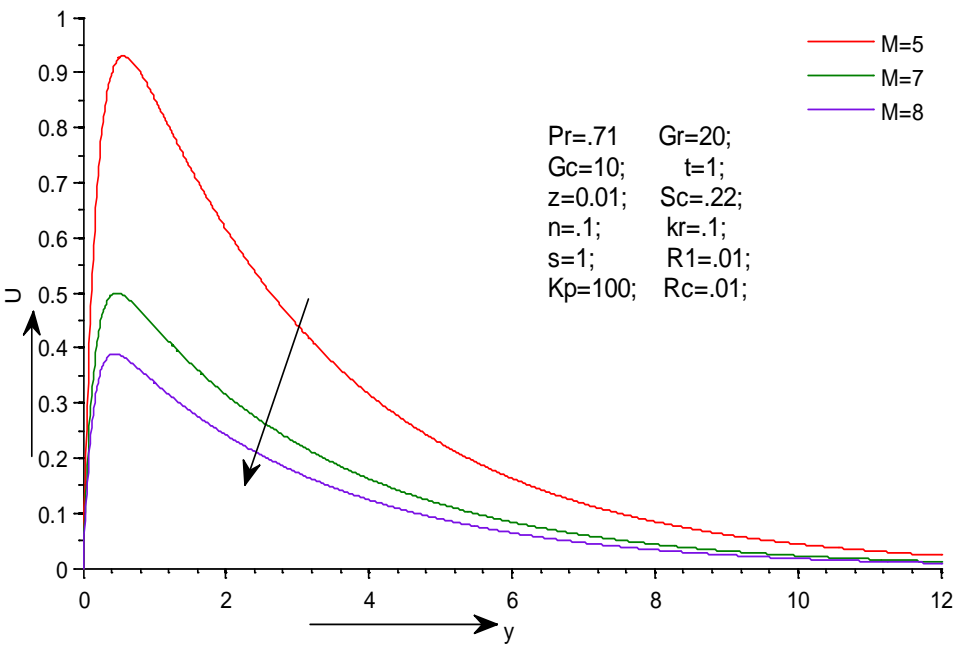

Figure 11. Effects of $M$ on velocity.

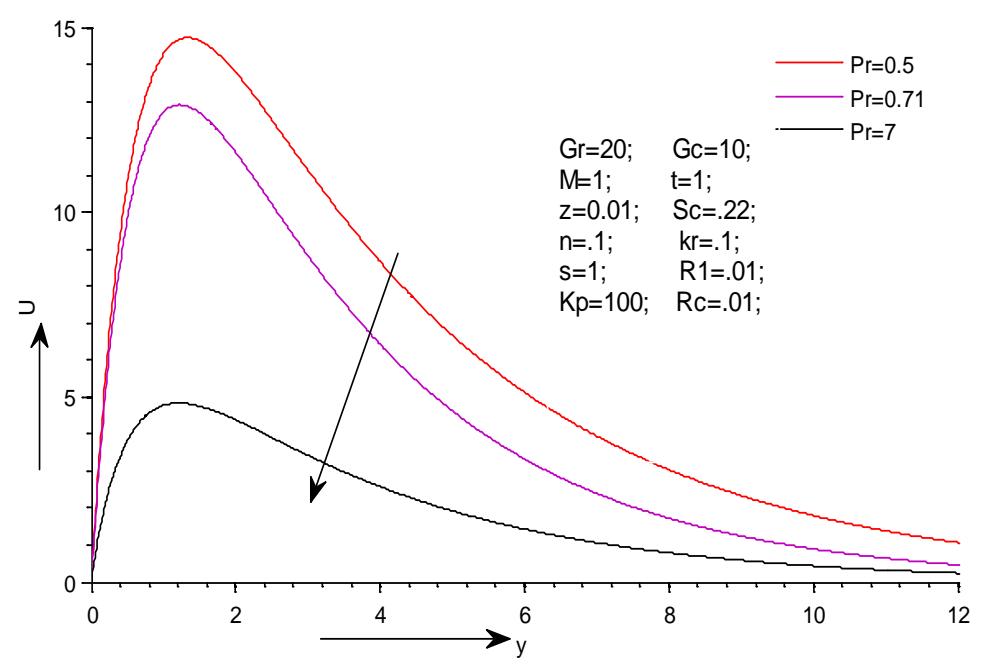

Figure 12. Effects of $\mathrm{Pr}$ on velocity. 


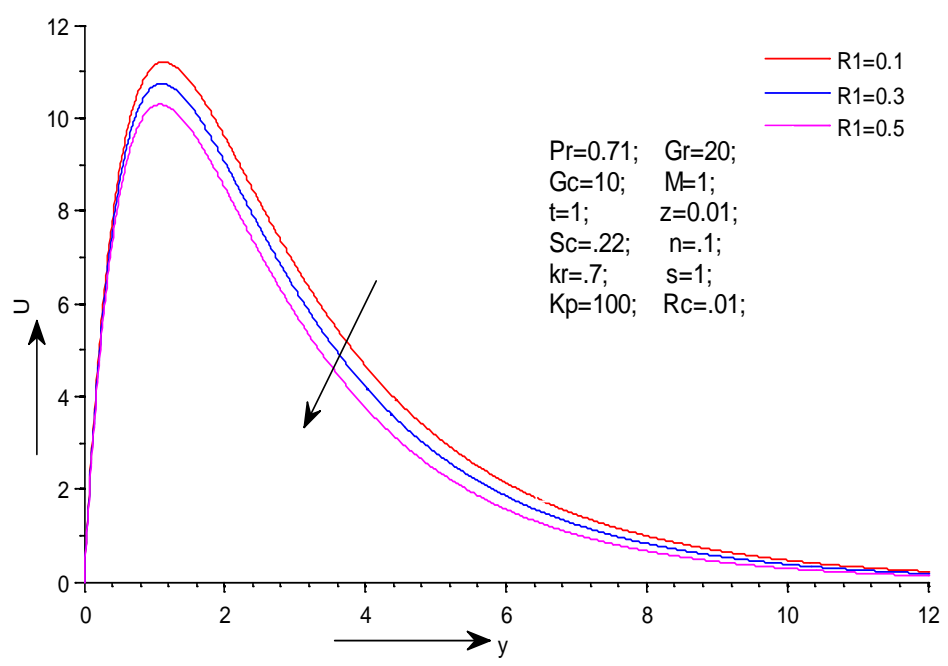

Figure 13. Effects of $R_{1}$ on velocity.

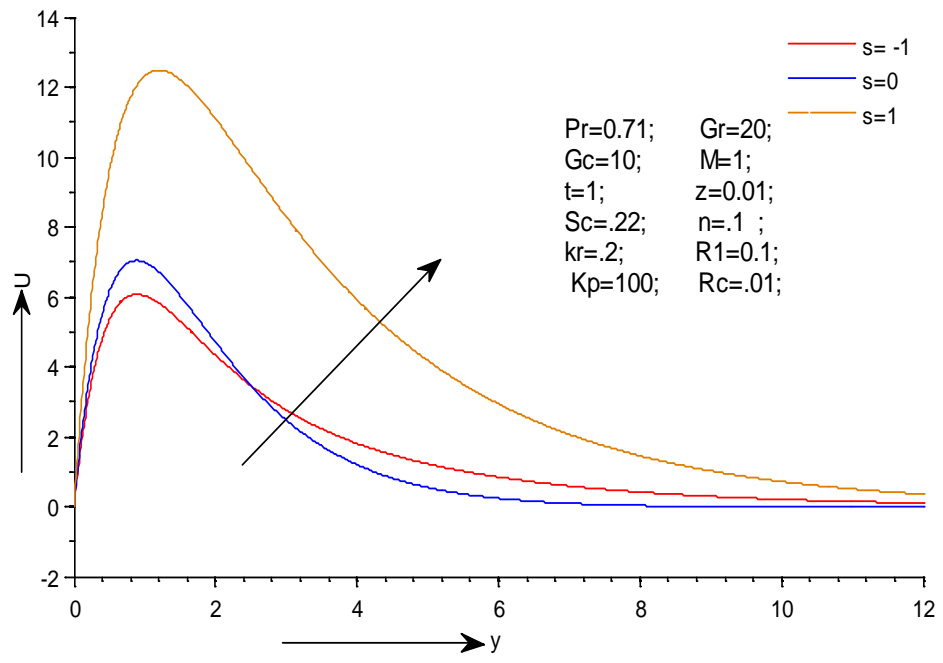

Figure 14. Effects of $S$ on velocity.

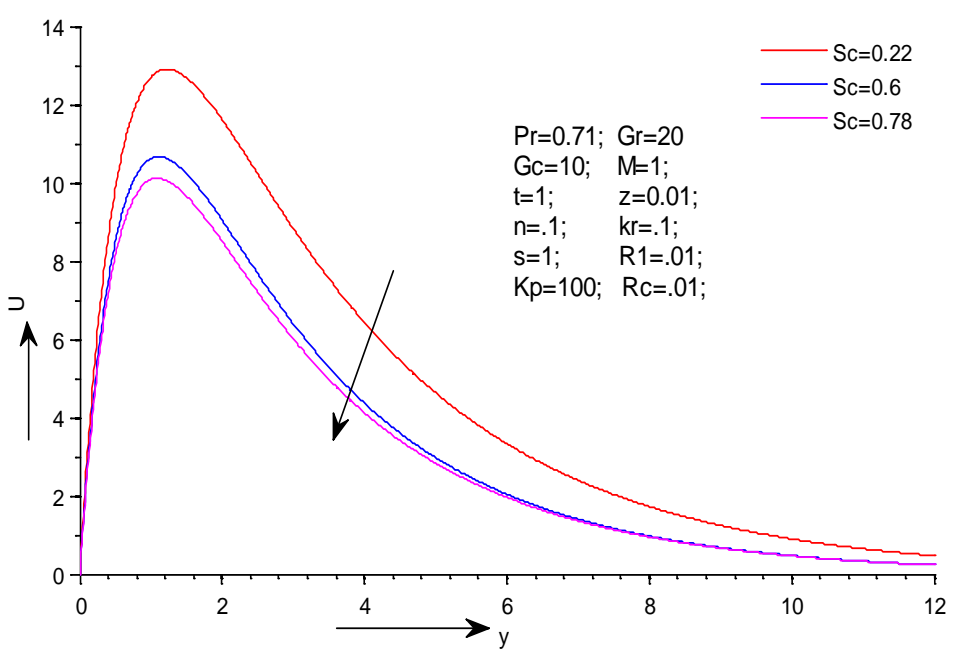

Figure 15. Effects of $S c$ on velocity. 
Table 1. Effect of $S c$ on skin friction, Sherwood number, Nusselt number, $\mathrm{z}=0.01, \mathrm{t}=1, \mathrm{n}=0.1$.

\begin{tabular}{ccccccccccccc}
\hline $\boldsymbol{P r}$ & $\boldsymbol{G r}$ & $\boldsymbol{G c}$ & $\boldsymbol{M}$ & $\boldsymbol{S c}$ & $\boldsymbol{K r}$ & $\boldsymbol{R} \mathbf{1}$ & $\boldsymbol{K p}$ & $\boldsymbol{R c}$ & $\boldsymbol{S}$ & $\boldsymbol{\tau}$ & Sh & Nu \\
\hline 0.71 & 20 & 10 & 1 & $\mathbf{0 . 2 2}$ & 0.1 & 0.1 & 100 & 0.1 & 1 & 1.7939 & 0.5513 & 0.3811 \\
0.71 & 20 & 10 & 1 & $\mathbf{0 . 6 6}$ & 0.1 & 0.1 & 100 & 0.1 & 1 & 3.9012 & 1.0714 & 0.4061 \\
0.71 & 20 & 10 & 1 & $\mathbf{0 . 7 8}$ & 0.1 & 0.1 & 100 & 0.1 & 1 & 5.5524 & 1.2913 & 0.4054 \\
\hline
\end{tabular}

Table 2. Effect of $\operatorname{Pr}$ on skin friction, Sherwood number, Nusselt number, $\mathrm{z}=0.01, \mathrm{t}=1, \mathrm{n}=0.1$.

\begin{tabular}{ccccccccccccc}
\hline $\boldsymbol{P r}$ & $\boldsymbol{G r}$ & $\boldsymbol{G} \boldsymbol{c}$ & $\boldsymbol{M}$ & $\boldsymbol{S c}$ & $\boldsymbol{K r}$ & $\boldsymbol{R 1}$ & $\boldsymbol{K p}$ & $\boldsymbol{R} \boldsymbol{c}$ & $\boldsymbol{S}$ & $\boldsymbol{\tau}$ & Sh & Nu \\
\hline 0.025 & 20 & 10 & 1 & $\mathbf{0 . 2 2}$ & 0.1 & 0.1 & 100 & 0.1 & 1 & 1.1192 & 0.2999 & 0.0194 \\
0.71 & 20 & 10 & 1 & $\mathbf{0 . 2 2}$ & 0.1 & 0.1 & 100 & 0.1 & 1 & 9.8535 & 0.2999 & 0.3518 \\
7 & 20 & 10 & 1 & $\mathbf{0 . 2 2}$ & 0.1 & 0.1 & 100 & 0.1 & 1 & 13.9820 & 0.2999 & 5.1590 \\
\hline
\end{tabular}

Table 3. Effect of $G r$ on skin friction, Sherwood number, Nusselt number, $\mathrm{z}=0.01, \mathrm{t}=1, \mathrm{n}=0.1$.

\begin{tabular}{ccccccccccccc}
\hline $\boldsymbol{P r}$ & $\boldsymbol{G r}$ & $\boldsymbol{G c}$ & $\boldsymbol{M}$ & $\boldsymbol{S c}$ & $\boldsymbol{K r}$ & $\boldsymbol{R 1}$ & $\boldsymbol{K p}$ & $\boldsymbol{R c}$ & $\boldsymbol{S}$ & $\boldsymbol{\tau}$ & Sh & Nu \\
\hline 0.71 & $\mathbf{1 0}$ & 10 & 1 & 0.22 & 0.1 & 0.1 & 100 & 0.1 & 1 & 6.5856 & 0.2999 & 0.3518 \\
0.71 & $\mathbf{1 5}$ & 10 & 1 & 0.22 & 0.1 & 0.1 & 100 & 0.1 & 1 & 8.2196 & 0.2999 & 0.3518 \\
0.71 & $\mathbf{2 0}$ & 10 & 1 & 0.22 & 0.1 & 0.1 & 100 & 0.1 & 1 & 9.8535 & 0.2999 & 0.3518 \\
\hline
\end{tabular}

Table 4. Effect of Gc on skin friction, Sherwood number, Nusselt number, $\mathrm{z}=0.01, \mathrm{t}=1, \mathrm{n}=0.1$.

\begin{tabular}{cccccccccccccc}
\hline $\boldsymbol{P r}$ & $\boldsymbol{G r}$ & $\boldsymbol{G c}$ & $\boldsymbol{M}$ & $\boldsymbol{S c}$ & $\boldsymbol{K r}$ & $\boldsymbol{R 1}$ & $\boldsymbol{K p}$ & $\boldsymbol{R c}$ & $\boldsymbol{S}$ & $\boldsymbol{\tau}$ & Sh & Nu \\
\hline 0.71 & 10 & $\mathbf{1 0}$ & 1 & 0.60 & 0.1 & 0.1 & 100 & 0.1 & 1 & 6.5856 & 0.2999 & 0.3518 \\
0.71 & 10 & $\mathbf{1 5}$ & 1 & 0.60 & 0.1 & 0.1 & 100 & 0.1 & 1 & 8.2444 & 0.2999 & 0.3518 \\
0.71 & 10 & $\mathbf{2 0}$ & 1 & 0.60 & 0.1 & 0.1 & 100 & 0.1 & 1 & 9.9033 & 0.2999 & 0.3518 \\
\hline
\end{tabular}

Table 5. Effect of $M$ on skin friction, Sherwood number, Nusselt number, $\mathrm{z}=0.01, \mathrm{t}=1, \mathrm{n}=0.1$.

\begin{tabular}{cccccccccccccc}
\hline $\boldsymbol{P r}$ & $\boldsymbol{G r}$ & $\boldsymbol{G c}$ & $\boldsymbol{M}$ & $\boldsymbol{S c}$ & $\boldsymbol{K r}$ & $\boldsymbol{R 1}$ & $\boldsymbol{K p}$ & $\boldsymbol{R} \boldsymbol{s}$ & $\boldsymbol{S}$ & $\boldsymbol{\tau}$ & Sh & Nu \\
\hline 0.71 & 10 & 10 & $\mathbf{1}$ & 0.22 & 0.1 & 0.1 & 100 & 0.1 & 1 & 6.5856 & 0.2999 & 0.3518 \\
0.71 & 10 & 10 & $\mathbf{2}$ & 0.22 & 0.1 & 0.1 & 100 & 0.1 & 1 & 2.9872 & 0.2999 & 0.3518 \\
0.71 & 10 & 10 & $\mathbf{5}$ & 0.22 & 0.1 & 0.1 & 100 & 0.1 & 1 & 2.7055 & 0.2999 & 0.3518 \\
\hline
\end{tabular}

Table 6. Effect of $K r$ on skin friction, Sherwood number, Nusselt number, $\mathrm{z}=0.01, \mathrm{t}=1, \mathrm{n}=0.1$.

\begin{tabular}{cccccccccccccc}
\hline $\boldsymbol{P r}$ & $\boldsymbol{G r}$ & $\boldsymbol{G} \boldsymbol{c}$ & $\boldsymbol{M}$ & $\boldsymbol{S c}$ & $\boldsymbol{K r}$ & $\boldsymbol{R 1}$ & $\boldsymbol{K p}$ & $\boldsymbol{R c}$ & $\boldsymbol{S}$ & $\boldsymbol{\tau}$ & Sh & Nu \\
\hline 0.71 & 10 & 10 & 1 & 0.22 & 0.1 & 0.1 & 100 & 0.1 & 1 & 6.5856 & 0.2999 & 0.3518 \\
0.71 & 10 & 10 & 1 & 0.22 & 0.3 & 0.1 & 100 & 0.1 & 1 & 8.5864 & 0.3955 & 0.3634 \\
0.71 & 10 & 10 & 1 & 0.22 & 0.5 & 0.1 & 100 & 0.1 & 1 & 10.0082 & 0.4662 & 0.3718 \\
\hline
\end{tabular}

Table 7. Effect of $K p$ on skin friction, Sherwood number, Nusselt number, $\mathrm{z}=0.01, \mathrm{t}=1, \mathrm{n}=0.1$.

\begin{tabular}{ccccccccccccc}
\hline $\boldsymbol{P r}$ & $\boldsymbol{G r}$ & $\boldsymbol{G} \boldsymbol{c}$ & $\boldsymbol{M}$ & $\boldsymbol{S c}$ & $\boldsymbol{K r}$ & $\boldsymbol{R} 1$ & $\boldsymbol{K p}$ & $\boldsymbol{R c}$ & $\boldsymbol{S}$ & $\boldsymbol{\tau}$ & $\mathbf{S h}$ \\
\hline 0.71 & 10 & 10 & 1 & 0.22 & 0.1 & 0.1 & 90 & 0.1 & 1 & $\mathbf{6 . 5 8 3 2}$ & 0.2999 \\
0.71 & 10 & 10 & 1 & 0.22 & 0.1 & 0.1 & 95 & 0.1 & 1 & $\mathbf{6 . 5 8 4 4}$ & 0.2999 & 0.3518 \\
0.71 & 10 & 10 & 1 & 0.22 & 0.1 & 0.1 & 100 & 0.1 & 1 & $\mathbf{6 . 5 8 5 6}$ & 0.2999 & 0.3518 \\
\hline
\end{tabular}


Table 8. Effect of $S$ on skin friction, Sherwood number, Nusselt number, $\mathrm{z}=0.01, \mathrm{t}=1, \mathrm{n}=0.1$.

\begin{tabular}{cccccccccccccc}
\hline $\boldsymbol{P r}$ & $\boldsymbol{G r}$ & $\boldsymbol{G c}$ & $\boldsymbol{M}$ & $\boldsymbol{S c}$ & $\boldsymbol{K r}$ & $\boldsymbol{R 1}$ & $\boldsymbol{K p}$ & $\boldsymbol{R c}$ & $\boldsymbol{S}$ & $\boldsymbol{\tau}$ & Sh & Nu \\
\hline 0.71 & 10 & 10 & 1 & 0.22 & 0.1 & 0.1 & 100 & 0.1 & $\mathbf{1}$ & 6.5856 & 0.2999 & 0.3518 \\
0.71 & 10 & 10 & 1 & 0.22 & 0.1 & 0.1 & 100 & 0.1 & $\mathbf{3}$ & 6.5808 & 0.2999 & 0.3568 \\
0.71 & 10 & 10 & 1 & 0.22 & 0.1 & 0.1 & 100 & 0.1 & $\mathbf{5}$ & 6.5799 & 0.2999 & 0.3577 \\
\hline
\end{tabular}

Table 9. Effect of $R c$ on skin friction, Sherwood number, Nusselt number, $\mathrm{z}=0.01, \mathrm{t}=1, \mathrm{n}=0.1$.

\begin{tabular}{cccccccccccccc}
\hline $\boldsymbol{P r}$ & $\boldsymbol{G r}$ & $\boldsymbol{G c}$ & $\boldsymbol{M}$ & $\boldsymbol{S c}$ & $\boldsymbol{K r}$ & $\boldsymbol{R 1}$ & $\boldsymbol{K p}$ & $\boldsymbol{R c}$ & $\boldsymbol{S}$ & $\boldsymbol{\tau}$ & Sh & Nu \\
\hline 0.71 & 10 & 10 & 1 & 0.22 & 0.1 & 0.1 & 100 & $\mathbf{0}$ & 1 & 17.7144 & 0.2999 & 0.3518 \\
0.71 & 10 & 10 & 1 & 0.22 & 0.1 & 0.1 & 100 & $\mathbf{0 . 0 5}$ & 1 & 3.2928 & 0.2999 & 0.3518 \\
0.71 & 10 & 10 & 1 & 0.22 & 0.1 & 0.1 & 100 & $\mathbf{0 . 2}$ & 1 & 1.3171 & 0.2999 & 0.3518 \\
\hline
\end{tabular}

Table 10. Effect of $R_{1}$ on skin friction, Sherwood number, Nusselt number, $\mathrm{z}=0.01, \mathrm{t}=1, \mathrm{n}=0.1$.

\begin{tabular}{cccccccccccccc}
\hline $\boldsymbol{P r}$ & $\boldsymbol{G r}$ & $\boldsymbol{G} \boldsymbol{c}$ & $\boldsymbol{M}$ & $\boldsymbol{S c}$ & $\boldsymbol{K r}$ & $\boldsymbol{R 1}$ & $\boldsymbol{K p}$ & $\boldsymbol{R c}$ & $\boldsymbol{S}$ & $\boldsymbol{\tau}$ & Sh & Nu \\
\hline 0.71 & 10 & 10 & 1 & 0.22 & 0.1 & 0.1 & 100 & $\mathbf{0 . 1}$ & 1 & 6.5856 & 0.2999 & 0.3518 \\
0.71 & 10 & 10 & 1 & 0.22 & 0.1 & 0.3 & 100 & $\mathbf{0 . 1}$ & 1 & 6.5993 & 0.2999 & 0.3375 \\
0.71 & 10 & 10 & 1 & 0.22 & 0.1 & 0.5 & 100 & $\mathbf{0 . 1}$ & 1 & 6.6130 & 0.2999 & 0.3232 \\
\hline
\end{tabular}

Figure 2 exhibits the effect of chemical reaction $(\mathrm{Kr})$ on concentration, it is noticed that the concentration of the fluid decreases as chemical reaction parameter increases. Figure 3 shows the effect of Schmidt number Sc on concentration when the values of $S c$ increases, the concentration value decreases. From Figure 4 we have noticed that temperature of the fluid increases as source or sink increases. Figure 5 shows the temperature profile for the different values of $S c$, from this figure we have noticed that increase in the value of Sc results in increase in the temperature profile. Figure 6 depicts the effect of $\mathrm{Kr}$ on temperature, when the values of $\mathrm{Kr}$ increases the temperature value increases. Figure 7 shows the effect of Prandtl number on temperature, when $\mathrm{Pr}$ value increases, the temperature decreases, similar type of results are noticed with Satyanarayana et al. [2]. Figure 8 depicts the effect of $G c$ on velocity, the velocity of the fluid increases when $G c$ increases. Figure 9 exhibits that the effect of $\mathrm{Gr}$ on velocity, from this figure we observed that, the velocity of the fluid increases when $\mathrm{Gr}$ increases. Figure 10 shows the effect of $K r$ on velocity, the velocity of the fluid decreases in the increase of $K r$. Figure 11 illustrates velocity profiles for different values of $M$, from this figure we have observed that velocity of the fluid decreases when an increase in the values of $M$. Figure 12 shows the velocity profile for different values of $\mathrm{Pr}$. It is observed that increase in the value of $\mathrm{Pr}$ results in decrease in the velocity profile. Figure 13 shows the velocity profile for different values of radiation absorption, from this figure it is noticed that an increase in the value of $R_{1}$ results a decrease in the velocity profile. Figure 14 illustrates the effect of source/sink on velocity, from this figure it is noticed that velocity of the fluid increases for decreasing values of source/sink. Figure 15 shows the effect of $S c$ on velocity, from this figure it is noticed that when $S c$ values increases the velocity of the fluid decreases. On the other hand, Tables 1-4 show, the effect of $S c, P r, G r$ and Gc on the parameters skin friction, Sherwood number, Nusselt number. It can be observed that skin friction coefficient increased with the increase in $S c, P r, G r, G c$. It can be clearly observed that rate of heat transfer of the fluid increases for increase in $S c$ and it is not shown any effect in case of $P r, G r, G c$. The Nusselt number increased as increase in the $S c$ and $P r$, but it is constant in the case of $G r$ and Gc. Further, Tables 5-10 show the effect of $M, K r, K p, S, R c$ and $R$ on the parameters skin friction, Sherwood number, Nusselt number. It can be observed that skin friction coefficient increased with an increase in $K r, K p, R c$, and $R_{1}$ whereas decreased in the increase of $M$ and $S$. The rate of the heat transfer of the fluid increases with an increase in $K r$, but it not shown any effect in case of $M, K p, S, R c$ and $R_{1}$. The Nusselt number increased with an increase in $K r, S$ and it is decreased with an increase in $R_{1}$. 


\section{Conclusions}

The present study is carried out to investigate the magneto convective flow of a non-Newtonian fluid through non-homogeneous porous medium past a vertical porous plate with variable suction. The dimensionless governing equations are solved by using the perturbation technique. The results for velocity and temperature are obtained and plotted graphically. The numerical results for skin friction and Nusselt number are computed in tables. The main conclusions of this study are as follows:

1. Velocity of the fluid increases with an increasing values of $S, G c, G r$. And it decreases in the case of $K r, S c$, $\operatorname{Pr}, M$ and $R_{1}$.

2. Temperature of the fluid increases with an increasing values of $K r, S c$ and $S$, whereas decreased in the case of $\mathrm{Pr}$.

3. $K r$ and $S c$ show negative impact on the concentration of the fluid.

4. Coeffecient of skin friction receives positive impact in case of $S c, \mathrm{Pr}, \mathrm{Gr}, \mathrm{Gc}, \mathrm{Kr}, \mathrm{Kp}, \mathrm{Rc}$, while negative effect in the case of $M$ and $S$. Sherwood number increases for increasing values of $S c$ and $K r$. Coefficient of rate of heat transfer increases with an increase in $\mathrm{Sc}, \mathrm{Pr}, \mathrm{Kr}$ and $\mathrm{S}$.

\section{References}

[1] Chaudhary, R.C. and Jain, P. (2006) Hall Effect on MHD Mixed Convection Flow of a Visco-Elastic Fluid past an Infinite Vertical Porous Plate with Mass Transfer and Radiation. Ukrainian Journal of Physics, 33, 281-309.

[2] Satyanarayana, P.V. (2013) MHD Free Convective Heat and Mass Transfer past a Vertical Porouse Plate with Variable Temperature. International Journal of Applied Mathematics and Mechanics, 9, 66-69.

[3] Kesavaiah, D.C., Satyanarayana, P.V. and Venkataramana, S. (2011) Effects of the Chemical Reaction and Radiation Absorption on Unsteady MHD Convective Heat and Mass Transfer Flow past a Semi-Infinite Vertical Permeable Moving Plate Embedded in Porous Medium with Heat Source and Suction. International Journal of Applied Mathematics and Mechanics, 7, 52-69.

[4] Venkata, S., Reddy, R. and Reddy, G.V. (2013) Effect of Chemical Reaction and Radiation Absorption on Unsteady MHD Double Diffusive Convective Flow of Viscous Fluid past a Semi-Infinite Porous Plate. International Journal of Advanced Engineering Technology, IV, 37-44.

[5] Raju, M.C., Varma, S.V.K. and Reddy, N.A. (2011) Radiation and Mass Transfer Effects on a Free Convection Flow through Porous Medium Bounded by a Vertical Surface. I-Manager Journal of Future Engineering and Technology, 7, 7-12.

[6] Muthucumarswamy, R. and Ganesan, P. (2001) First Order Chemical Reaction on Flow past an Impulsively Started Vertical Plate with Uniform Heat and Mass Flux. Acta Mechanica, 14, 45-57. http://dx.doi.org/10.1007/bf01182351

[7] Das, U.N., Deka, R. and Soundalgekar, V.M. (1995) Effects of Mass Transfer on a Flow past an Impulsively Started Infinite Vertical Plate with Constant Heat Flux and Chemical Reaction. Forschung im Ingenieurwesen, 60, 284-287.

[8] Kandasamy, R., Perisamy, K. and Prabhu, S. (2005) Chemical Reaction, Heat and Mass Transfer on MHD Flow over a Vertical Stretching Surface with Heat Source and Thermal Stratification Effects. International Journal of Heat and Mass Transfer, 48, 4557-4561. http://dx.doi.org/10.1016/j.ijheatmasstransfer.2005.05.006

[9] Alam, M.S., Rahman, M.M. and Sattar, M.A. (2008) Effects of Chemical Reaction and Thermophoresis on MHD Mixed Convective Heat and Mass Transfer Flow along an Inclined Plate in the Presence of Heat Generation/Absorption with Viscous Dissipation and Joule Heating. Canadian Journal of Physics, 86, 1057-1066.

[10] Muthucumaraswamy, R. and Kulaivel, T. (2003) Chemical Reaction Effects on Moving Infinite Vertical Plate with Uniform Heat Flux and Variable Mass Diffusion. Forschung im Ingenieurwesen, 68, 101-104.

[11] Mahapatra, M., Dash, G.C., Panda, S. and Acharya, M. (2010) Effects of Chemical Reaction on Free Convection Flow through a Porous Medium Bounded by a Vertical Surface. Journal of Engineering Physics and Thermophysics, 83, 130-140. http://dx.doi.org/10.1007/s10891-010-0327-1

[12] Mishra, S.R. and Dash, G.C. (2013) Mass and Heat Transfer Effect on MHD Flow of a Viscoelastic Fluid through Porous Medium with Oscillatory Suction and Heat Source. International Journal of Heat and Mass Transfer, 57, 433438. http://dx.doi.org/10.1016/j.ijheatmasstransfer.2012.10.053

[13] Beg, O.A., Takhar, H.S., Kumari, M. and Nath, G. (2001) Computational Fluid Dynamics Modelling of Buoyancy Induced Viscoelastic Flow in a Porous Medium with Magnetic Field Effects. International Journal of Applied Mechanics and Engineering, 6, 187-210.

[14] Soundalgekar, V.M., Gupta, S.K. and Birajdar, N.S. (1979) Effects of Mass Transfer and Free Convection Effects on MHD Stokes Problem for a Vertical Plate. Nuclear Engineering and Design, 53, 309-346. 
[15] Kandasamy, R., Perisamy, K. and Sivagnana Prabhu, K.K. (2005) Effects of Chemical Reaction, Heat and Mass Transfer along a Wedge with Heat Source and Concentration in the Presence of Suction or Injection. International Journal of Heat and Mass Transfer, 48, 1388-1394.

[16] Singh, G. (2012) Mass Transfer with Chemical Reaction in MHD Mixed Convection Flow along a Vertical Stretching Sheet. International Journal of Engineering \& Technology, 4, 1-12.

[17] Sivaiah, M. (2010) Radiation Effects on MHD Free-Convection Flow over a Vertical Plate with Heat and Mass Flux. Emirates Journal for Engineering Research, 15, 35-40.

[18] Ahmed, S. (2012) Laplace Technique on MHD Radiating and Chemically Reacting Fluid over an Infinite Vertical Surface. International Journal of Engineering \& Technology, 2, 684-693.

[19] Singh, A.K. and Singh, N.P. (2003) Heat and Mass Transfer in MHD Flow of a Viscous Fluid Past a Vertical Plate Under Oscillatory Suction Velocity. Indian Journal of Pure and Applied Mathematics, 34, 429-442.

[20] Reddy, M.G. (2014) Thermal Radiation and Chemical Reaction Effects on MHD Mixed Convective Boundary Layer Slip Flow in a Porous Medium with Heat Source and Ohmic Heating. The European Physical Journal Plus, $129,41$. http://dx.doi.org/10.1140/epjp/i2014-14041-3

[21] Rout, B.R. (2014) Effect of Radiation and Chemical Reaction on Natural Convective MHD Flow through a Porous Medium with Double Diffusion. Journal of Engineering Thermophysics, 23, 53-65. http://dx.doi.org/10.1134/S181023281401007X

[22] Prakash, J. (2014) Effects of Chemical Reaction and Radiation Absorption on MHD Flow of Dusty Viscoelastic Fluid. Applications and Applied Mathematics, 9, 141-156.

[23] Kesavaiah, C.D. (2012) Radiation Absorption, Chemical Reaction and Magnetic Field Effects on Free Convection and Mass Transfer Flow through Porous Medium with Constant Suction and Constant Heat Flux. International Journal of Scientific Engineering and Technology, 1, 274-284.

[24] Raju, M.C., Varma, S.V.K. and Rao, R.R.K. (2013) Unsteady MHD Free Convection and Chemically Reactive Flow past an Infinite Vertical Porous Plate. Journal of Future Engineering and Technology, 8, 35-40.

[25] Umamaheswar, M., Varma, S.V.K. and Raju, M.C. (2013) Unsteady MHD Free Convective Visco-Elastic Fluid Flow Bounded by an Infinite Inclined Porous Plate in the Presence of Heat Source, Viscous Dissipation and Ohmic Heating. International Journal of Advanced Science and Technology, 61, 39-52. http://dx.doi.org/10.14257/ijast.2013.61.05

[26] Reddy, T.S., Raju, M.C. and Varma, S.V.K. (2012) Chemical Reaction and Radiation Effects on Unsteady MHD Free Convection Flow near a Moving Vertical Plate. Journal of Future Engineering \& Technology, 7, 11-20.

[27] Rajesh, V. and Varma, S.V.K. (2010) Radiation Effects on MHD Flow through a Porous Medium with Variable Temperature or Variable Mass Diffusion. International Journal of Applied Mathematics and Mechanics, 6, 39-57.

[28] Kesavaiah, C.D. and Satyanarayana, P.V. (2012) Radiation and Mass Transfer Effects on Moving Vertical Plate with Variable Temperature and Viscous Dissipation. International Journal of Mathematical Archive, 3, 3028-3035.

[29] Ravikumar, V., Raju, M.C. and Raju, G.S.S. (2014) Combined Effects of Heat Absorption and MHD on Convective Rivlin-Ericksen Flow past a Semi-Infinite Vertical Porous Plate. Ain Shams Engineering Journal, 5, 867-875. http://dx.doi.org/10.1016/j.asej.2013.12.014

[30] Venkateswarlu, B. and Satya Narayana, P.V. (2015) Chemical Reaction and Radiation Absorption Effects on the Flow and Heat Transfer of a Nanofluid in a Rotating System. Applied Nanoscience, 5, 351-360.

[31] Mishra, S.R., Das, G.C. and Acharya, M. (2013) Mass and Heat Transfer Effect on MHD Flow of a Visco-Elastic Fluid through Porous Media with Oscillatory Suction and Heat Source. International Journal of Heat and Mass Transfer, 57, 433-438. http://dx.doi.org/10.1016/j.ijheatmasstransfer.2012.10.053

[32] Raju, M.C. and Varma, S.V.K. (2011) Unsteady MHD Free Convection Oscillatory Couette Flow through a Porous Medium with Periodic Wall Temperature. Journal on Future Engineering and Technology, 6, 7-12.

[33] Raju, M.C. and Varma, S.V.K. (2014) Soret Effects Due to Natural Convection in a Non-Newtonian Fluid Flow in Porous Medium with Heat and Mass Transfer. Journal of Naval architecture and Marine Engineering, 11, 147-156. http://dx.doi.org/10.3329/jname.v11i2.17563 


\section{Appendix}

$m_{1}=\frac{S_{c}+\sqrt{S_{c}^{2}+4 S_{c} \kappa_{r}}}{2}$

$$
A_{1}=\frac{S_{c} m_{1}}{m_{1}^{2}-m_{1} S_{c}-S_{c}\left(\kappa_{r}+\frac{n}{4}\right)}
$$

$m_{5}=\frac{P_{r}+\sqrt{P_{r}^{2}-4 S P_{r}}}{2}$

$$
A_{6}=\frac{A_{3}}{m_{3}^{2}-m_{3} P_{r}+P_{r}\left(S-\frac{n}{4}\right)}
$$

$$
\begin{aligned}
& A_{9}=-\left(G_{c}+A_{2} G_{r}\right), \\
& A_{10}=-G_{r}\left(1-A_{2}\right),
\end{aligned}
$$

$$
\begin{gathered}
A_{13}=-\left(A_{11}+A_{12}\right), \\
m_{11}=m_{9},
\end{gathered}
$$

$$
A_{16}=\frac{A_{12} m_{5}^{2}}{m_{5}^{2}-m_{5}-\left(M^{2}+\frac{1}{\kappa_{p}}\right)}
$$

$$
A_{20}=m_{5} A_{12}-A_{8} G_{r}-\frac{A_{12}}{\kappa_{p}}
$$

$$
A_{23}=\frac{A_{18}}{m_{9}^{2}-m_{9}-\left(M^{2}+\frac{1}{\kappa_{p}}+\frac{n}{4}\right)},
$$

$$
A_{25}=\frac{A_{20}}{m_{5}^{2}-m_{5}-\left(M^{2}+\frac{1}{\kappa_{p}}+\frac{n}{4}\right)},
$$

$$
A_{26}=\frac{A_{21}}{m_{3}^{2}-m_{3}-\left(M^{2}+\frac{1}{\kappa_{p}}+\frac{n}{4}\right)},
$$

$$
A_{28}=-\left(A_{23}+A_{24}+A_{25}+A_{26}+A_{27}\right) \text {, }
$$

$$
m_{3}=\frac{S_{c}+\sqrt{S_{c}^{2}+4 S_{c}\left(\kappa_{r}+\frac{n}{4}\right)}}{2}
$$

$$
A_{2}=\frac{R_{1} P_{r}}{m_{1}^{2}-m_{1} P_{r}+S P_{r}}, \begin{aligned}
& A_{3}=R_{1} P_{r}\left(1-A_{1}\right) \\
& A_{4}=\left(R_{1} A_{1}+m_{1} A_{2}\right) P_{r} \\
& A_{5}=m_{5} P_{r}\left(1-A_{2}\right)
\end{aligned}
$$

$m_{7}=\frac{P_{r}+\sqrt{P_{r}^{2}-4 P_{r}\left(S-\frac{n}{4}\right)}}{2}$

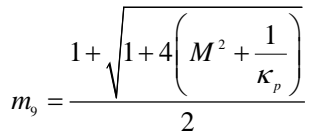

$$
A_{7}=\frac{A_{4}}{m_{1}^{2}-m_{1} P_{r}+P_{r}\left(S-\frac{n}{4}\right)}
$$

$$
A_{8}=\frac{A_{5}}{m_{5}^{2}-m_{5} P_{r}+P_{r}\left(S-\frac{n}{4}\right)}
$$

$A_{11}=\frac{A_{9}}{m_{1}^{2}-m_{1}-\left(M^{2}+\frac{1}{\kappa_{p}}\right)}$

$$
A_{12}=\frac{A_{10}}{m_{5}^{2}-m_{5}-\left(M^{2}+\frac{1}{\kappa_{p}}\right)}
$$

$A_{14}=\frac{A_{13} m_{9}^{3}}{m_{9}^{2}-m_{9}-\left(M^{2}+\frac{1}{\kappa_{p}}\right)}$

$$
A_{15}=\frac{A_{11} m_{1}^{3}}{m_{1}^{2}-m_{1}-\left(M^{2}+\frac{1}{\kappa_{p}}\right)}
$$

$$
A_{17}=-\left(A_{14}+A_{15}+A_{16}\right) \text {, }
$$

$$
A_{18}=m_{9} A_{13}-\frac{A_{13}}{\kappa_{p}},
$$

$$
A_{19}=-G r\left(1-A_{6}-A_{1}-A_{8}\right) \text {, }
$$

$A_{21}=-\left(A_{6} G_{r}+G_{c}\left(1-A_{1}\right)\right)$,

$$
A_{22}=m_{1} A_{11}-A_{1} G_{r}-A_{1} G_{c}-\frac{A_{11}}{\kappa_{p}},
$$

$$
m_{13}=\frac{1+\sqrt{1+4\left(M^{2}+\frac{1}{\kappa_{p}}+\frac{n}{4}\right)}}{2},
$$

$$
A_{27}=\frac{A_{22}}{m_{1}^{2}-m_{1}-\left(M^{2}+\frac{1}{\kappa_{p}}+\frac{n}{4}\right)},
$$

$$
A_{29}=\frac{n}{4} m_{13}^{2} A_{28}+m_{13}^{3} A_{28}
$$




$$
\begin{aligned}
& A_{30}=m_{11} A_{17}-\frac{A_{17}}{K_{p}} \quad A_{31}=m_{9} A_{14}-\frac{A_{14}}{\kappa_{p}}+A_{13} m_{9}^{3}+\frac{n}{4} m_{9}^{2} A_{23}+m_{9}^{3} A_{23}, \\
& A_{32}=\frac{n}{4} m_{7}^{2} A_{24}+m_{7}^{3} A_{27} \quad A_{33}=m_{5} A_{16}-\frac{A_{16}}{\kappa_{p}}+A_{12} m_{5}^{3}+\frac{n}{4} m_{5}^{2} A_{25}+m_{5}^{3} A_{25} \\
& A_{34}=\frac{n}{4} m_{3}^{2} A_{26}+m_{3}^{3} A_{26}, \quad m_{15}=m_{13,} \\
& A_{35}=\frac{n}{4} m_{1}^{2} A_{27}+m_{1}^{3} A_{27}+m_{1} A_{15}+m_{1}^{3} A_{11}-\frac{A_{15}}{K_{p}}, \\
& A_{36}=\frac{A_{29}}{m_{13}^{2}-m_{13}-\left(M^{2}+\frac{1}{\kappa_{p}}+\frac{n}{4}\right)}, \\
& A_{37}=\frac{A_{30}}{m_{11}^{2}-m_{11}-\left(M^{2}+\frac{1}{K_{p}}+\frac{n}{4}\right)}, \\
& A_{38}=\frac{A_{31}}{m_{9}^{2}-m_{9}-\left(M^{2}+\frac{1}{\kappa_{p}}+\frac{n}{4}\right)}, \\
& A_{39}=\frac{A_{32}}{m_{7}^{2}-m_{7}-\left(M^{2}+\frac{1}{\kappa_{p}}+\frac{n}{4}\right)}, \\
& A_{40}=\frac{A_{33}}{m_{5}^{2}-m_{5}-\left(M^{2}+\frac{1}{\kappa_{p}}+\frac{n}{4}\right)}, \\
& A_{41}=\frac{A_{34}}{m_{3}^{2}-m_{3}-\left(M^{2}+\frac{1}{\kappa_{p}}+\frac{n}{4}\right)} \text {, } \\
& A_{42}=\frac{A_{35}}{m_{1}^{2}-m_{1}-\left(M^{2}+\frac{1}{\kappa_{p}}+\frac{n}{4}\right)}, \\
& A_{44}=R_{c} A_{17} \\
& A_{46}=A_{12}+R_{c} A_{16}, \quad A_{47}=A_{11}+R_{c} A_{15}, \\
& A_{49}=A_{28}+R_{c} A_{36}, \quad A_{50}=R_{c} A_{37}, \\
& A_{48}=R_{c} A_{43}, \quad A_{51}=A_{23}+R_{c} A_{38}, \\
& A_{52}=A_{24}+R_{c} A_{39} \\
& A_{53}=A_{25}+R_{c} A_{40} \text {, } \\
& A_{43}=-\left(A_{36}+A_{37}+A_{38}+A_{39}+A_{40}+A_{41}+A_{42}\right) \text {, } \\
& A_{45}=A_{13}+R_{c} A_{14}, \\
& A_{54}=A_{26}+R_{c} A_{41}, \quad A_{55}=A_{27}+R_{c} A_{42},
\end{aligned}
$$

\section{Nomenclature}

C0: Species concentration

$\mathrm{C}$ : Non-dimensional species concentration

D: Molecular diffusivity

Gc: Grashof number for mass transfer

Gr: Grashof number for heat transfer

g: Acceleration due to gravity

K0: Permeability of the medium

Kp: Permeability/porosity parameter

$\mathrm{k}$ : Thermal diffusivity

M: Magnetic parameter

$\mathrm{N}$ : Nusselt number

Pr: Prandtl number $\varepsilon$ : a small positive constant

S: Heat source parameter

Sc: Schmidt number

Sh: Sherwood number
$\mathrm{R}_{1}$ : Radiation absorption.

Kr: Chemical reaction

M: Magnetic parameter

$\mathrm{B}_{0}$ : Magnetic field of uniform strength

$\sigma$. Electrical conductivity

$\rho$ : Density of the fluid

$\mathrm{t}$ : Time

$\beta$ : Volumetric coefficient of expansion for heat transfer

$\beta^{*}$ : Volumetric coefficient of expansion with species concentration

$\mathrm{R}_{\mathrm{c}}$ : Elastic parameter.

$v$ : Kinematic coefficient of viscosity.

$v_{0}$ : Constant suction velocity. 